\title{
O DISFARCE DA FORÇA
}

\author{
Ivonil Parraz* \\ parraz@uol.com.br
}

RESUMO Neste artigo pretendemos analisar a definição de justiça que Pascal oferece, tal como ela se apresenta no "reino da concupiscência". Para ele, a justiça é "prevenção da sedição" (La 66; B.326). Prevenir qualquer revolta é a garantia da paz no Estado. Para tanto, não basta a arte do bem governar, ressaltada nos "Trois discours sur la condition des grands", é preciso usar a força. Ora, como a força não se deixa manipular por se tratar de uma qualidade palpável, ao passo que a justiça se presta a isso, por ser uma qualidade espiritual, manipula-se a justiça para justificar a força. Esvaziado o velho conceito dejustiça: "dar a cada um o que lhe é devido", esta passa a ser o disfarce da força.

Palavras-chave Justiça; Força; Costume; Concupiscência

ABSTRACT In this article we intend to analyze the definition of justice in the "realm of concupiscence" given by Pascal. Justice is, according to him, prevention of sedition (L. 66; B. 326). Preventing any revolt is the guarantee of peace in the State. Pascal points out in the Trois discours sur la condition des grandes that the good art in governing is not enough to achieve this goal. It is necessary to use force. Because force cannot be manipulated since it is a tangible quality unlike justice, which is a spiritual quality, justice is manipulated to justify force. Once the traditional concept of justice as "give every one his due" becomes empty, justice becomes the disguise of force.

Keywords Justice; Force; Custom; Concupiscence

\footnotetext{
* Professor de Filosofia na Faculdade João Paulo II - FAJOPA (Marília/SP). Artigo recebido entre 1ํ e 30 de abril de 2006 e aprovado entre $1^{\circ}$ e 31 de maio de 2006.
}

KRITERION, Belo Horizonte, $n^{\circ}$ 114, Dez/2006, p. 259-271. 
Pascal apresenta o homem na Natureza como “(...) um nada em relação ao infinito, um tudo com relação ao nada, um meio entre nada e tudo, infinitamente afastado de compreender os extremos; o fim das coisas e seus princípios estão para ele invencivelmente escondido num segredo impenetrável (...)" (La 199; B. 72). A ciência da natureza é de tal modo desprovida de fundamentos que nada revela acerca da essência ou da finalidade do mundo. Do mesmo modo, a análise pascaliana da política a apresenta como carente de fundamentação. “(...) Preso numa pequena cela (...)” (La 199; B.72) no universo infinito, o homem pascaliano encontra-se, em sociedade, lançado, à sua revelia, numa "ilha desconhecida".

Nesta ilha desconhecida, em que cada indivíduo julga ser "rei e imperador", devido a concupiscência, esta que é causa e conseqüência da queda, "todos os homens se odeiam naturalmente uns aos outros. Usou-se como se pôde da concupiscência para fazê-la servir ao bem público. Mas isso não passa de fingimento e de uma falsa imagem da caridade, pois no fundo não é mais do que ódio" (La 210; B. 451). "Foram fundamentadas e tiradas da concupiscência regras admiráveis de política, de moral e de justiça. Mas, no fundo, esse feio fundo do homem, esse fingimentum malum está apenas encoberto. Não está desaparecido" (La 211; B. 453).

Se em sociedade a concupiscência humana está apenas encoberta, nela os homens são guiados pela cupidez. A sociedade humana é então um verdadeiro reino da concupiscência, no qual todos os homens querem dominar e nem todos podem. Ela se apresenta como dividida entre dominantes e dominados. O partido dominante toma o poder e se mantém pela força. A força é aquela que se encontra na base da sociedade dos homens. Somente a força é capaz de moderar a ambição humana.

Se aqueles que dominam somente pela força, não há um Direito Natural nem um apanágio divino que os façam situar, natural ou sobrenaturalmente, acima dos demais, concedendo a eles um verdadeiro direito de governar. Neste reino da concupiscência, a justiça é, tal como Pascal a define, "a previsão da sedição" (La 66; B. 326), pois ela impede que a falta de justiça que está na base da sociedade seja conhecida por todos. Ora, se a justiça é aquela que previne a revolta, as leis do Estado, visando à justiça, são estabelecidas pela força. Como então o povo passou a obedecer às leis e a respeitar os dominantes? Quais os meios utilizados para isso? E qual o artifício humano para que as leis fossem justificadas, ou seja, como a justiça, heterogênea à força, passou a ser o seu disfarce? 


\section{Imaginação}

"Imaginação. É essa parte dominante do homem, essa mestra do erro e da falsidade (...)” (La 44; B. 82). A imaginação é uma potência, e uma potência dominante. Tamanha é a força dessa potência que os homens valorizam as pequenas coisas e desvalorizam as grandes; ela leva os homens a crença. Ninguém resiste a força da imaginação.

(...) Nossos magistrados conheceram bem esse mistério. As suas togas vermelhas, os arminhos com que se acalentam, os palácios onde julgam, as flores-de-lis, todo esse aparato augusto era bem necessário, e se os médicos não tivessem batas e mulas, e se os doutores não tivessem barretes quadrados e roupas muito amplas de quatro partes, jamais teriam podido enganar o povo, que não pode resistir a essa exibição tão autêntica. Se tivessem a verdadeira justiça, e se os médicos tivessem a verdadeira arte de curar, não teriam o que fazer com os seus barretes quadrados (...), mas só possuindo ciências imaginárias é necessário que lancem mão desses vãos instrumentos que tocam a imaginação a que eles fazem apelo e mediante isso, de fato, provocam respeito (...) (La 44: B. 82).

Togas vermelhas, arminhos, flores-de-lis, batas, barretes quadrados, todos esses vãos instrumentos são necessários para mascarar a ausência da verdadeira justiça e da verdadeira arte de curar. Como também, surpreendendo a imaginação daqueles que assistem essa vitrina tão autêntica, arrancar deles o respeito e a crença de que eles possuem a ciência verdadeira. Uma vez obtidos a crença e o respeito pela força da imaginação, os magistrados, que também não resistem a tal força, passam a crer que eles, de fato, possuem um verdadeiro saber.

Nossos reis não “(...) procuram essas fantasias. Não se disfarçam com roupas extraordinárias para parecerem extraordinários (...)" (La 44; B. 82). Os reis dispensam esses disfarces em suas aparições públicas, pois “(...) se fazem acompanhar por guardas, por homens com cicatrizes. Essas tropas armadas que só têm mãos e força para eles, as trombetas e os tambores que marcham à frente e essas legiões que os cercam fazem tremer os mais firmes. Eles não têm a roupa, mas têm a força (...)" (La 44; B. 82). Acostumado a ver o rei sempre acompanhado por "tropas armadas", o povo acredita que ele, dispondo de toda força, possui o verdadeiro poder. "As trombetas e os tambores que marcham à sua frente", anunciam tal poder. A crença no poder do rei faz com que o povo o venere a ponto de dizer que: “(...) o caráter da divindade está impresso em seu rosto" (La 25; B. 308). O rei "não precisa de roupas extraordinárias para parecer extraordinário", porque o exército armado que o acompanha reveste o seu corpo em corpo de majestade. É com este corpo multiplicado que o povo vê o rei. E este, por sua vez, que também não resiste à força da imaginação, 
se vê com os olhos do povo: vê a si mesmo como é visto. O rei vê a si como um outro a tal ponto de o jovem Luís XIV afirmar: "o Estado sou eu" (Marin, 1997, p. 139). Não somente o povo crê que o rei é o detentor de todo poder, mas também o próprio rei acredita que ele é detentor de um poder absoluto.

É próprio da imaginação, devido à credibilidade que ela suscita, dar consistência de realidade às aparências. “(...) A imaginação dispõe de tudo; faz a beleza, a justiça e a felicidade que é tudo no mundo (...)" (La 44; B. 82). É pela força dessa potência dominante que o povo, obedecendo às leis, crê obedecer à justiça que imagina. A imaginação é um expediente indispensável para que o partido dominante, mesmo assumindo o poder e aí se mantendo pela força, consegue arrancar do povo o reconhecimento e a obediência.

\section{Força e Justiça}

Conseguindo o respeito público, o partido dominante pode exercer sua força instituindo as leis, e estas, por sua vez, transformam-se em costume e, com isso, evitam a destruição recíproca, uma vez que, nesse reino da concupiscência, todos julgam ser "reis e imperadores". Revestida em lei e em costume, a força evita a guerra civil e consegue a paz do Estado.

O maior dos males para Pascal são as guerras civis (La 94; B. 313); e a paz é o bem soberano do Estado (La 81; B. 299). A guerra civil é o maior dos males, pois nela a concupiscência aflora. Todos os homens, guiados pela cupidez, visam exclusivamente aos seus interesses. Todos querem dominar. A guerra civil é a guerra de todos contra todos. E o bem soberano do Estado é a paz, ou seja, quando os interesses da maioria são minimamente satisfeitos; quando a cupidez, satisfeita, permanece encoberta. Esta paz aparente só é alcançada se as revoltas forem inibidas. Com efeito, se a justiça é definida como a prevenção da revolta, e se esta é obtida somente quando a concupiscência dos homens é de algum modo satisfeita, podemos afirmar que para Pascal a justiça encontrase vazia de sua substancialidade: proporcionar a cada um o que lhe é devido. Não se trata mais de um direito natural que cada indivíduo pudesse dispor e que, uma vez não respeitado, ele teria o direito de reclamá-lo; e o dever do governante seria oferecer a ele o que lhe é devido, mas simplesmente de ceder minimamente aos interesses da maioria.

Esta arte de governar, ou seja, satisfazer aos interesses da maioria, Pascal a apresenta ao jovem duque nos "Trois discours sur la condition des grands":

Estais cercado de um pequeno número de pessoas, sobre as quais reinais à vossa maneira. Essas pessoas estão cheias de concupiscência. Elas vos pedem os bens da concupiscência; é a concupiscência que as liga a vós. Portanto, sois propriamente 
um rei de concupiscência. Vosso reino é de pequena extensão; mas nisso sois igual aos maiores reis da terra; tanto quanto vós, eles são reis de concupiscência. É a concupiscência que faz sua força, isto é, a posse das coisas que a cupidez dos homens deseja.

Mas conhecendo vossa condição natural [que o mantém numa perfeita igualdade com todos os homens], usais os meios que ela oferece e não pretendais reinar por outro caminho, a não ser por aquela que vos faz rei [que é aquele estabelecido pelos homens]. Não é vossa força e vossa potência natural que submete a vós todas as pessoas. Não pretendais, portanto, dominá-las pela força, nem tratá-las com dureza. Satisfazei seus justos desejos; aliviai suas necessidades, tendo prazer em ser bondoso; fazei o possível para que elas progridam e estareis agindo como verdadeiro rei de concupiscência (Pascal, 1963, p. 368).

Se o que uni governantes e governados é a concupiscência, a única maneira de governar consiste em contentar a cupidez dos homens. Fazendo com que eles obedeçam às leis julgando obedecer à justiça que imaginam. Neste reino da concupiscência, o único modo de conseguir a paz é prevenir toda e qualquer sedição.

Todavia, se a concessão aos interesses da maioria é necessária para prevenir a revolta, ela não é suficiente. É preciso usar de outros artifícios para inibir qualquer motim. Para atingir tal fim, os homens uniram a justiça à força.

No fragmento La 85; B. 878, Pascal sustenta ser impossível por a força nas mãos da justiça, por isso puseram a justiça nas mãos da força. Isto porque a força não se deixa manipular, uma vez que se trata de uma "qualidade palpável", ao passo que a justiça é uma "qualidade espiritual" e, como tal, pode-se dispô-la como se queira. Não podendo manipular a força, manipulouse a justiça. Desse modo, a força passou a ser justa: “(...) assim se chama justo aquilo que é forçoso observar (...)” (La 85; B. 878).

Por a justiça nas mãos da força implica forjar a justiça para justiçar a força. Somente justificando a força é possível adequar a justiça ao reino da concupiscência. Apenas desse modo pode-se dar a aparência de justiça à sociedade dos homens, cujo laço é a cupidez.

Sobre que fundamentará o homem e a economia do mundo que quer governar? Será sobre o capricho de cada indivíduo? Que confusão! Será sobre a justiça? Ele a ignora. Certamente se ele a conhecesse não teria estabelecido essa máxima, a mais geral de todas as que existem entre os homens, que cada um siga os costumes do seu país. O esplendor da verdadeira eqüidade teria subjugado todos os povos (...) (La 60; B. 294).

O governo do mundo não pode se fundamentar nem no capricho dos homens, nem na justiça. O primeiro porque cada indivíduo, movido pela 
cupidez, visaria aos seus próprios interesses e não ao bem comum, o que acarretaria uma confusão absurda, e a própria governabilidade destruiria-se por seu próprio fundamento. $\mathrm{O}$ segundo porque os homens desconhecem a justiça. A prova desta ignorância, Pascal a encontra na máxima mais geral de todas: "que cada um siga os costumes de seu país" (La 60; B. 294). Ora, se a verdadeira justiça fosse conhecida pelos homens, ela deveria governar todos os povos. Os limites geográficos dos países não limitariam a justiça: “(...) justiça engraçada essa que um rio limita (...)" (La 60; B. 294). Assim, os povos não teriam nada a fazer com os costumes do seu país, pois estariam subjugados pela justiça.

Os costumes são transmitidos de geração a geração e, assim, são estabelecidos sem que se possa assinalar sua origem. E, do mesmo modo que não se pode assinalar sua origem, também não se pode assinalar seu fim, uma vez que eles podem mudar: "(...) em poucos anos de posse, as leis fundamentais mudam; o direito tem suas épocas (...)" (La 60; B. 294). Ora, se os costumes podem mudar de tempos em tempos e passam a ser a máxima mais seguida de cada país, e posto as leis, que regem os povos, se sustentar nos costumes, o Estado se fundamenta em bases bastante frágeis. Suas leis são flutuantes.

“(...) O costume (é) toda a eqüidade, pela simples e só razão de que é recebido (...)" (La 60; B. 294). O costume, recebido por todos, leva-os a julgar que ele é justo, uma vez que todos o recebem. Sua autoridade reside no fato de todos os homens seguí-lo. Sendo o costume toda a eqüidade, e posto as leis fundamentais do Estado sustentar-se nele, isso implica que não há leis naturais comuns a todos os países que subjugassem todos os povos. “(...) Existem sem dúvida leis naturais, mas essa bela razão corrompida tudo corrompeu (...)" (La 60; B. 294).

Os interesses dos indivíduos corrompem a razão humana, o desejo de poder e a força da imaginação. Corrompida a razão, as leis naturais deixam de ser seguidas pelos homens e, em seu lugar, o costume passa a ser aquele que iguala todos eles, uma vez que todos o recebem: “(...) pode haver algo mais engraçado do que o fato de um homem ter o direito de me matar porque mora do outro lado da água e porque o seu príncipe tem alguma desavença com o meu, embora eu não tenha nenhuma desavença com ele próprio? (...)" (La 60; B. 294)

Por se estar subjugada pelo costume, pelo fato de as leis fundamentais do Estado estarem sustentadas por ele, a justiça só pode ser definida como a "prevenção da sedição", pois “(...) a arte de intrigar, subverter os estados está em abalar os costumes estabelecidos, sondando até a sua fonte para apontarlhes a falta de autoridade e de justiça (...)" (La 60; B. 294). Abalam-se os 
costumes estabelecidos quando se vai até sua fonte mostrando a sua falta de autoridade e de justiça. Ora, como as leis do Estado se sustentam nos costumes estabelecidos, abalando estes, destrói-se aquele. Assim, a revolta, essa "arte de intrigar", "é um jogo certo para perder tudo" (La 60; B. 294). A justiça, como "prevenção da sedição", impede que a falta de justiça e de autoridade que se encontram na base do Estado venham à tona. A justiça passa a ser, então, aquela que impede que a ausência de justiça, pela qual os homens deixam-se governar, seja conhecida. Em outros termos: a justiça estabelecida é aquela que impede que a não justiça do Estado seja conhecida. Para que haja paz - e é isso o que visa a justiça estabelecida -, é preciso ocultar aos homens no que se baseiam as leis do Estado.

No fragmento La 86; B. 297, Pascal ressalta a ausência da verdadeira justiça na sociedade dos homens: "Veri Juris. Não o temos mais. Se tivéssemos, não tomaríamos como regra de justiça seguir os costumes do país. Foi aí que, não podendo encontrar o justo, encontrou-se o forte etc". O verdadeiro direito e a pura justiça nos são ausentes: "não as temos mais". O homem não é, então, guiado pela idéia de justiça. Por isso mesmo é que se tomam os costumes do país como regras de justiça. O verbo régler nos Pensamentos comporta uma idéia de resignação, tal como nos aponta Laurent Thirouin: "regra-se um fenômeno na falta de dominá-lo, de compreendê-lo, quando se renuncia apoderar-se de sua verdadeira organização" (Thirouin, 1991, p. 68). Com efeito, tomam-se os costumes como regras de justiça, porque não se compreende a verdadeira justiça.

Não sendo possível seguir a idéia de justiça para estabelecer as leis, esta que seria a expressão concreta daquela, a sociedade dos homens começa com a força: “(...) imaginemos que a vemos a se formar. Acontece sem dúvida que eles irão se bater até que a parte mais forte oprima a mais fraca, e que finalmente haja um partido dominante (...)" (La 828; B. 304). A força passa a ser o fundamento do costume, pois este é estabelecido por aquela: "a força é a rainha do mundo (...) é ela que faz a opinião" (La 554; B. 303); se é bravo ou assassino segundo "o lado da água" (La 51; B. 293). O costume, estabelecido pela força, é generalizado em justiça: “(...) não podendo fazer com que fosse forçoso obedecer à justiça, fez-se com que fosse justo obedecer à força" (La 81; B. 299).

A força encontra-se na base da sociedade dos homens, e não a justiça. Se esta fosse a sua origem e a sua fonte, seria o seu fim. É pela força e não pela justiça que o partido dominante toma o poder, e aí se mantém. Também é por ela que o povo deixa-se governar, uma vez que o costume é estabelecido por ela e depois generalizado em justiça. 
"A justiça é o que está estabelecido; e assim todas as nossas leis estabelecidas serão tidas necessariamente como justas sem ser examinadas, visto que estão estabelecidas" (La 645; B. 312). A justiça estabelecida não obedece à idéia de justiça, uma vez que os homens ignoram a verdadeira justiça. Por qual via ela se estabelece? Não somente a justiça é estabelecida, mas também as leis. Estas são estabelecidas pela força. Por que então elas são necessariamente tidas como justas sem mesmo serem examinadas? Por que essa necessidade? Porque elas são estabelecidas pela força. Se a força estabelece as leis e, portanto, estabelece a si mesma como justa, não se discute essa justiça. Não se discute com a força. A qualidade da força é palpável. Não há o que ser examinado. Ela se impõe por sua qualidade. As leis, instituídas pela força, possuem o poder de inibir qualquer revolta. Com efeito, se a justiça é a "prevenção da sedição", as leis são necessariamente tidas como justas. É a força então que passa a ser justa. A justiça é apenas uma construção humana baseada na força. Instrumento útil para evitar a guerra civil: a guerra de todos contra todos.

Se na sociedade dos homens a força é que é justa, a justiça não é fortificada pela instituição das leis. Estabelecidas pela força, as leis não são a expressão concreta da verdadeira justiça. Mas se as leis, uma vez estabelecidas, são tidas como justas, é a força que é justificada. Justificando a força, a justiça passa a ser o seu disfarce.

No fragmento La 103; B. 298, intitulado “justiça, força”, Pascal expõe o modo pelo qual a força passou a ser justificada.

É justo que o que é justo seja seguido; é necessário que o que é o mais forte seja
seguido. A justiça sem a força é impotente; a força sem a justiça é tirânica. A justiça
sem força é contradita, porque sempre existem pessoas más. A força sem a justiça é
acusada. É preciso, pois, colocar juntas a justiça e a força e, para isso, fazer com que
aquilo que é justo seja forte ou que o que é forte seja justo. A justiça está sujeita à
discussão. A força é bem reconhecível e sem discussão. Assim, não se pôde dar força
à justiça, porque a força contradisse a justiça e disse que ela era injusta, e disse que
era ela, a força, que era justa. E assim, não podendo fazer com que o que é justo fosse
forte, fez-se com que o que é forte fosse justo.

Pascal inicia o texto sustentando que "é justo que o que é justo seja seguido; é necessário que o que é o mais forte seja seguido". Duas afirmações que se opõem. A justiça impõe a si mesma sem recorrer ao Ser e ao Bem. Ela não necessita de nenhum argumento, seja ele de utilidade ou de persuasão. Isto porque a justiça é justa por si mesma, por isso é justo segui-la. Não há graus na justiça como há na força. Não há um mais justo e um menos justo. Se é justo ou não. Há justiça ou não há. O que não é justo é injusto. “(...) A justiça e a 
verdade são duas pontas tão sutis que os nossos instrumentos são demasiados cegos para nelas tocar com exatidão. Se conseguirem, vão achatar-lhes a ponta e apoiar à volta toda mais sobre o falso do que sobre o verdadeiro (...)" (La 44; B. 82). A ponta da justiça não admite degraus que vão do injusto ao justo.

Enquanto a justiça impõe a si mesma, a força se impõe como uma necessidade física, mecânica, uma vez que sua qualidade é palpável: “essas tropas armadas que só têm mãos e força para os reis, as trombetas e os tambores que marcham à sua frente e essas legiões que os cercam fazem tremer os mais firmes (...). Eles têm a força” (La 44; B. 82). A aparição pública do rei é o momento em que ele manifesta a sua força. Todo o séqüito que o acompanha é signo de força. O povo, dominado pela imaginação e adestrado pelo costume, treme diante da exibição da força.

Enquanto não há graus na justiça, há graus na força: "é necessário que o mais forte seja seguido". Para que seja necessariamente seguido, o mais forte precisa manifestar sua força. Ao manifestar sua força, o mais forte oprime a força mais fraca. "As cordas que amarram o respeito de uns para com os outros em geral são cordas de necessidade; pois é preciso que haja diferentes graus, por quererem todos os homens dominar e nem todos o poderem, mas apenas alguns poderem (...)" (La 828; B. 304). A simples aparição pública do rei, manifestando a sua força, aniquila as outras forças. Aniquilação sem guerra, nem palavras. É a visão autêntica da qualidade palpável da força. Sua visão impõe o silêncio: "ela faz tremer os mais firmes".

"A justiça sem a força é impotente; a força sem a justiça é tirânica." A justiça não tem força, pois, ignorada no reino da concupiscência, ninguém é obrigado e ninguém se obriga a seguí-la. Seguí-la é justo simplesmente porque a justiça é justa. No reino da concupiscência, em que cada um visa aos seus próprios interesses, não há nenhum atrativo em ser justo. A justiça não recompensa ninguém pelo fato de ser justo. Não tendo a força, a justiça é, em si mesma, impotente: é um nada de força. A tirania, que é a força sem a justiça, é, por sua vez, o todo da força. Violência pura. A força sem a justiça traz consigo o desejo de ser a maior força, o desejo de aniquilar as outras forças. Quanto mais elevada for a maior força, mais as outras forças encontram-se aniquiladas. $\mathrm{O}$ tirano é aquele que deseja a destruição de toda outra força.

A tirania consiste no desejo de domínio universal e fora de sua ordem. Diversos compartimentos de fortes, de belos, de bons espíritos, de piedosos, dos quais cada um reina na sua parte, não noutra parte. E às vezes se encontram, e o forte se bate com o belo como tolos disputando quem terá o domínio do outro, porque o seu domínio é de gênero diverso. Não se entendem. E o erro deles está em querer reinar por toda parte. Nada o pode, nem mesmo a força: ela nada faz no reino dos sábios, ela só tem 
o domínio das ações exteriores (...). A tirania está em querer ter por um caminho o que só pode ter por outro (La 58; B. 332).

Pascal oferece duas definições de tirania, isto é, da força sem a justiça. A primeira a define como aquela que deseja dominar todas as outras forças, inclusive aquelas de outras ordens: ordem do espírito e ordem da caridade. A segunda a define como aquela que deseja ser reconhecida como a maior força pelas forças das outras ordens. A tirania é própria da ordem do corpo, uma vez que ela "só tem o domínio das ações exteriores", ela "nada faz no reino dos sábios". Duas definições de tirania que no fundo são a mesma coisa: desejo de aniquilar todas as outras forças e desejo de ser admirado e amado por esse domínio universal.

"A justiça sem força é contradita, porque sempre existem pessoas más." A justiça sem força, que se impõe por si mesma como justa, é contradita pelas pessoas más. Estas, que sempre existiram, contradiz a justiça por suas próprias ações. Ora, se as pessoas más se opõem à justiça, elas se impõem, por suas ações, como justas. Para elas, a justiça é que é injusta. A existência de pessoas más contradiz a justiça.

"A força sem a justiça é acusada." A força sem a justiça, manifestando a sua força, reduz as outras forças ao silêncio. Quem então acusa a força? Enquanto as pessoas más contradizem a justiça sem força, é a justiça sem a força que acusa a força sem a justiça. Mas de que a justiça acusa a força? A força é a primeira qualidade manifestada pelo partido dominante e continua a ser pela imposição das leis. A força é então a qualidade das leis e, uma vez que estas são tidas como justas, torna-se o conteúdo da justiça (Lazzari, 1993, p. 249). Assim, a justiça sem a força acusa a falta de justiça da força.

"É preciso, pois, por juntas a justiça e a força e, para isso, fazer com que aquilo que é justo seja forte ou que o que é forte seja justo." Mas como colocá-las juntas se até agora o que vimos foi elas operarem em campos opostos? A justiça sem força não pode realizar nenhum ato justo, visto que ela é impotente. $\mathrm{E}$ a força sem a justiça só realiza ato de pura força, inclusive fora do seu domínio. A afirmação inicial do fragmento: "é justo que o que é justo seja seguido" é contradita pelas pessoas más: por aqueles que têm a força sem a justiça. Ora, estes, por suas ações, diz que a justiça é injusta. Assim, a força sem a justiça opõe àquela afirmação uma outra: "é injusto que o que é justo seja seguido" (Marin, 1997, p. 121). "É necessário que o que é o mais forte seja seguido": à esta afirmação, também inicial do fragmento, se opõe a justiça que acusa a força. Ora, se a força é acusada pela justiça, é a força que é injusta. A justiça sem força opõe àquela afirmação uma outra: "é injusto que o que é o mais forte seja seguido" (Marin, 1997, p. 121). 
A força contradizendo a justiça e a justiça acusando a força mostra claramente que elas se excluem. Havendo exclusão, como "fazer com que aquilo que é justo seja forte ou que o que é forte seja justo"? Para isto é preciso identificar justiça e força, fazendo com que a força passe a ser uma qualidade da justiça ou que a justiça passe a ser uma qualidade da força. É preciso decidir sobre estas duas alternativas. A primeira delas é impossível de ser realizada: “(...) se tivesse sido possível, ter-se-ia posto a força na mão da justiça, mas como a força não se deixa manipular como se quer por se tratar de uma qualidade palpável, ao passo que a justiça é uma qualidade espiritual de que se dispõe como se quer (...)" (La 85; B.878). A justiça, ao contrário da força, é uma idéia: sua qualidade é espiritual enquanto a da força é palpável. Assim, primeiro não se pode obrigar alguém a seguir a justiça, uma vez que sua qualidade é espiritual; segundo, não se atribui uma qualidade palpável ao que só possui uma qualidade espiritual.

"A justiça está sujeita a discussão. A força é bem reconhecível e sem discussão." Por ser uma idéia essencial, a justiça é objeto de discussões polêmicas. Ela é objeto de discurso dos filósofos que desenvolvem inúmeros argumentos pesquisando sobre o que é o justo. A força, ao contrário, não está sujeita a discussão. Ela é "bem reconhecível", sua "qualidade é palpável". Não há um discurso da força, sua qualidade dispensa qualquer discurso. Nem também um discurso contra a força, porque não há argumentos diante do mais forte. Em face dele, os menos fortes se calam. "Isso é admirável: não se quer que eu preste honras a um homem vestido de brocados e seguido de 7 ou 8 lacaios. O quê! Ele mandará me dar correiadas se eu não o saudar. Aquela roupa é uma força (...)" (La 89; B. 315). A roupa, como também o séqüito que acompanha o rei e os vãos instrumentos dos doutores se transformam em signos, e signos da força.

"Assim, não se pôde dar força à justiça, porque a força contradisse a justiça e disse que ela era injusta, e disse que era ela, a força, que era justa." Em primeiro lugar, a força contradisse a justiça ao ser instituída como lei, tornando-se o conteúdo da justiça. Ela então pode dizer que a justiça é injusta e é ela que é justa. Em segundo lugar, a força, que não está sujeita a discussão, tem o direito de falar: "ela disse que...". A força se apropria dos signos da linguagem e passa a se representar em signos. "Ela se converte em sentido". Disso resulta que a força é cada vez menos visível no exercício do poder. E, por isso, o povo acredita estar obedecendo não pela imposição da força, mas a algo perfeitamente legítimo. A apropriação dos signos de linguagem pela força é movida pelo desejo de dominação universal e fora de sua ordem. Representada em signos, a força exerce o seu poder fora do seu domínio (que 
são as ações exteriores). Com o direito de falar, a força se institui. Ela faz a lei, que é sua lei, e por ela se legitima. Pela lei, que é sua lei, a força se autoriza. Ela tem então o direito de falar porque tem o poder da fala. $\mathrm{O}$ discurso da força é, portanto, o discurso do poder (Marin, 1997, p. 125).

A força não discute o que é a justiça e o que é o justo: "ela disse que a justiça era injusta, e disse que era ela que era justa". Justificando a si mesma, a força se apodera da justiça. O mais forte é o justo. É então injusto afrontar a força. Eis aqui o momento de transformação radical no texto. Pascal inicia o fragmento sustentando que: "é justo que o que é justo seja seguido; é necessário que o que é o mais forte seja seguido". Se o mais forte é o justo e se é injusto afrontar a força, é justo que o mais forte seja seguido.

"E assim, não podendo fazer com que o que é justo fosse forte, fez-se com que o que é forte fosse justo." Sujeita a discussões intermináveis, não se pôde fortificar a justiça. Dizendo que é ela que é justa, a força atribui a si mesma uma qualidade espiritual. Aquela que só tinha uma qualidade palpável passou a ter uma qualidade espiritual. Esta não está sujeita a discussão, pois o seu sujeito é a força e não uma idéia. Por essa qualidade espiritual, a força pôde estender o seu domínio a outras ordens. Assim, o que é, na ordem do pensamento, heterogêneo: força e justiça passaram a ser, na ordem do vivido, unidas.

Justificando a si mesma, a força se instituiu, e a justiça passou a ser o seu disfarce. A força, disfarçada em justiça, estabeleceu a ordem no reino da concupiscência: "não se podendo fortificar a justiça, justificou-se a força, a fim de que o justo e o forte estivessem juntos e que houvesse paz, que é o soberano bem" (La 81; B. 299). A paz, no reino da concupiscência, é então fruto da justificação da força. Por isso que a justiça estabelecida deve ser aquela que "previne a sedição", pois, caso contrário, haveria a subversão da ordem, ou seja, a guerra civil: "o pior dos males". Essa paz obtida através da justificação da força, porém, não consegue eliminar a concupiscência, apenas a encobre.

Os homens passaram a conviver em paz, apesar da concupiscência. Mas, para que essa convivência fosse pacífica, foi preciso adequar a justiça ao reino da concupiscência.

\section{Referências Bibliográficas}

CHEVALLEY, C. Pascal contingence et probabilités. Paris: PUF, 1995.

LAZZARI, C. Force et justice dans la politique de Pascal. Paris: PUF, 1993.

MARIN, L. Pascal et Port-Royal. Paris: PUF, 1997. 
PASCAL, B. Pensamentos. Trad. Sérgio Milliet. São Paulo: Nova Cultural, 1988. (Col. Os Pensadores).

. Pensamentos. Trad. Mário Laranjeiras. São Paulo: Martins Fontes, 2001. . Trois discours sur la condition des grands. In: PASCAL, B. Euvres

Complètes. Ed. Louis Lafuma. Paris: Seuil, 1963. p. 366-368.

THIROUIN, L. Le hasard et les règles: le modèle du jeu dans la Pensée de Pascal. Paris: J. Vrin, 1991. 